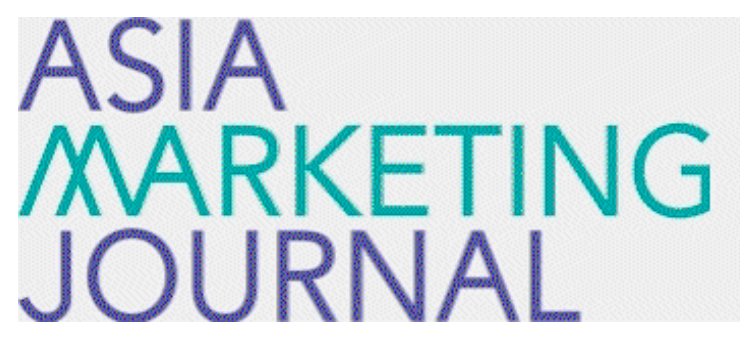

ASIA MARKETING JOURNAL

Volume 1 | Issue 4

Article 3

$9-1-1999$

\title{
신제품 개발조직의 지식역량 향상에 관한 연구
}

형준 김

Follow this and additional works at: https://amj.kma.re.kr/journal

Part of the Marketing Commons

\section{Recommended Citation}

김, 형준 (1999) "신제품 개발조직의 지식역량 향상에 관한 연 구," Asia Marketing Journal: Vol. 1 : Iss. 4 , Article 3.

Available at: https://doi.org/10.53728/2765-6500.1024

This Article is brought to you for free and open access by Asia Marketing Journal. It has been accepted for inclusion in Asia Marketing Journal by an authorized editor of Asia Marketing Journal. 


\title{
신제품 개발조직의 지식역량 향상에 관한 연구.
}

\author{
김 형준(서울대학교 경영대학 경영연구소 연구원)
}

mariokim@plaza.snu.ac.kr

\section{[국문초록]}

지식사회, 지식경제의 등장과 더불어 기업의 자원으로서 지식(knowledge)의 중요성이 부각됨에 따라 마케팅 전략의 한 분야로서의 신제품 전략에서도 신제품 개발과정에 있 어 기업(혹은 신제품 개발 팀)의 지식과 지식의 활용 능력을 어떻게 확장할 것인가가 중 요한 전략적 이슈(issue)가 된다. 신제품 개발 과정에서는 필연적으로 불확실성-시장 불 확실성과 기술 불확실성-이 존재하며 불확실성을 해소하기 위하여 정보와 지식의 중요성 이 부각되고 기업내의 다양한 조직-특히 R\&D, 생산, 마케팅-과의 지식공유. 통합과정이 중요시된다.

이에 따라 본 연구는 첫째, 기업이 가지고 있는 지식을 제품으로 구체화하는 과정이 신제품 개발(New Product Development; NPD)과정이며 구체화 과정에서 개발의 효율성과 효과성을 어떻게 달성할 것인가에 관한 문제를 다루고자 한다. 둘째, 기존의 신제품 성 과 요인으로 제시되고 있는 많은 요인들을 '지식역량(knowledge competence)'의 개념으로 정리하고 이러한 지식 역량과 신제품 경쟁우위 간의 인과적 관계를 살펴봄으로써 신제 품 경쟁우위에 어떠한 영향을 미치는가에 대한 분석을 하고자 한다. 셋째 신제품 개발조 직의 지식역량을 향상시키기 위한 전략적 방안을 제시하고자 한다. 이론적 배경으로 기 업을 지식의 결집체로 인식하고 있는 지식거점관점(knowledge based perspective)과 이러한 지식자원의 활용에 초점을 맞춘 조직학습(organizational learning) 이론 그리고 심리학에서 다루고 있는 분산된 인지이론(distributed cognition theory)을 활용한다.

* 논문접수: 99.9 게재확정: 99.11

1999. 9 


\section{1. 서론}

신제품 개발과 출시에 따른 기업의 혜택도 다양하지만 실패로 인한 기업의 위험도 상당 하다. 신제품이 기업의 성공과 실패 또는 이익에 중요한 영향을 미친다는 것은 새삼스러운 것이 아니다. 기업의 판매에서 신제품이 차지하는 비중이 1980 년대의 30\%에서 1985-90 년 사이에 $42 \%$ 로 증가하였고 이러한 수치는 앞으로 5 년 이내에 $52 \%$ 로 증가할 것으로 예측되 고 있다(Kleinschmidt \& Cooper, 1995). 그러나 신제품 성공률은 $60 \%$ 에도 미치지 못하는 것으 로 조사되고 있다. ${ }^{1}$ 제품 수명주기의 단축, 경쟁의 범세계화, 기술변화속도의 격변과 같은 기 업 환경의 변화로 인하여 기업의 신제품 개발의 동인이 증가하고 있으나 신제품의 개발에 따르는 여러 가지 문제로 인하여 제품의 개발에 어려움이 존재하며 잘못된 신제품 개발은 상당한 매몰비용(sunk cost)을 부담하여야 하며 기술적인 폐쇄(technology lock-in)로 인하여 경 쟁기업과의 기술격차가 벌어지게 되는 기회비용도 부담하여야 한다.

신제품이 시장에서 성공하기 위한 조건에 대한 연구는 다양하게 이루어져 왔다. 특히 지 식사회, 지식경제의 등장과 더불어 기업의 자원으로서 지식(knowledge)의 중요성이 부각됨에 따라 생산 요소로서의 지식에 대한 관리(지식관리; knowledge management) 효율적인 지식의 획득과 활용(조직 학습; organizational learning), 그리고 학습을 효율적, 효과적으로 수행하는 조직 특성(학습조직; learning organization)에 대한 관심이 증가하고 있으며 마케팅 전략의 한 분야인 신제품 전략에서도 기업(혹은 신제품 개발 팀)의 지식과 지식의 활용 능력을 어떻게 확장할 것인가가 중요한 전략적 이슈(issue)로 등장하고 있다.

이에 따라 본 연구는 다음과 같은 내용을 다루고자 한다. 첫째, 기업이 가지고 있는 지식 을 제품으로 구체화하는 과정을 신제품 개발(New Product Development; NPD)과정으로 파악하 여 구체화 과정에서의 효율성과 효과성을 어떻게 달성할 것인가에 관한 문제를 다루고자 한 다. 둘째, 기존의 신제품 성과 요인으로 제시되고 있는 많은 요인들을 '지식역량(knowledge competence)'의 개념으로 정리하고 이러한 지식 역량과 신제품 경쟁우위 간의 인과적 관계를 살펴봄으로써 신제품 경쟁우위에 어떠한 영향을 미치는가에 대한 분석을 하고자 한다. 셋째 신제품 개발조직의 지식역량을 향상하기 위한 전략적 방안을 제시하고자 한다. 기업을 지식

${ }^{1}$ ) 출시 단계에서의 신제품 성공률은 영국의 경우 $54.3 \%$, 일본은 $59.8 \%($ Scott et al, 1992), 미국은 $55 \%$ (Maidique \& Zirger, 1984)로 나타나고 있다.

2 ) 신제품개발에 필요한 대안적인 기술들이 다양하게 존재하는 경우 하나의 기술 선택에 따른 기술궤적의 형성은 이러한 기술이 시장에서 우세한(표준화된) 기술이 되지 못하는 경우 기술이 사양화. 진부화되는 위험이 존재한다. 기술 전환에 따르는 시간압축의 비경제성(누적성)의 특성은 기술전환에 상당한 시간을 요하게 된다. 정보통신산업, 전자산업에서 이러한 예가 다양하게 나타나고 있다. 
결집체로 인식하고 있는 지식거점관점(knowledge based perspective)과 지식자원의 활용에 초점 을 맞춘 조직학습(organizational learning) 이론, 분산된 인지이론(distributed cognition theory)을 이론적 배경으로 삼는다.

\section{2. 신제품 개발 연구에서의 새로운 접근법}

\section{1 과거 연구의 흐름}

신제품 개발에 관한 기존 연구는 신제품 개발과정을 합리적인 계획화(rational plan)의 과 정, 의사소통 그물망(communication web), 또는 훈련된 문제해결(disciplined problem solving) 과 정으로 인식하여 왔다(Brown \& Eisenhardt, 1995).

[표 1] 신제품 개발 연구 흐름의 비교 평가

\begin{tabular}{|c|c|c|c|}
\hline 연구 흐름 & $\begin{array}{l}\text { 합리적인 계획화 } \\
\text { (Rational Plan) }\end{array}$ & $\begin{array}{c}\text { 커뮤니케이션 웹 } \\
\text { (Communication } \\
\text { Web) }\end{array}$ & $\begin{array}{c}\text { 문제해결의 과정 } \\
\text { (Disciplined Problem } \\
\text { Solving) }\end{array}$ \\
\hline 주요 아이디어 & $\begin{array}{l}\text { 우수 제품, 매력적 시장, } \\
\text { 합리적 조직을 통한 성공 }\end{array}$ & $\begin{array}{c}\text { 내부와 외부 커뮤 } \\
\text { 니케이션을 통한 } \\
\text { 성공 }\end{array}$ & $\begin{array}{c}\text { 훈련된 문제해결과정을 } \\
\text { 통한 성공 }\end{array}$ \\
\hline 이론 & 비이론적 & 정보와 자원의존 & $\begin{array}{c}\text { 문제해결을 포함한 정 } \\
\text { 보 }\end{array}$ \\
\hline 제품 & $\begin{array}{l}\text { 제품 우위-원가, 품질, 독 } \\
\text { 특성, 핵심역량과 적합성 }\end{array}$ & & $\begin{array}{c}\text { 제품 통합-고객과 기업 } \\
\text { 에 적합한 제품 비젼 }\end{array}$ \\
\hline 시장 & 규모, 성장, 경쟁 & & \\
\hline 상위 경영층 & 지원 & & 미묘한 통제 \\
\hline 프로젝트 팀 & 기능간(X-Functional) 팀 & & 기능간(X-Functional) 팀 \\
\hline 의사소통 & 기능간에 높은 의사소통 & $\begin{array}{c}\text { 내부/외부 의사소 } \\
\text { 통 }\end{array}$ & 내부 의사소통 \\
\hline 작업 조직 & 계획화와 효과적인 실행 & & $\begin{array}{c}\text { 중첩된 단계, 테스팅. } \\
\text { 순환반복, 계획화 }\end{array}$ \\
\hline 프로젝트 리더 & & $\begin{array}{l}\text { 정치적 능력을 가 } \\
\text { 진 소집단 관리자 }\end{array}$ & 유력한 리더 \\
\hline 고객 & 초기 몰입 & & \\
\hline 공급자 & 초기 몰입 & & 높은 몰입 \\
\hline 성과(종속변수) & $\begin{array}{c}\text { 제품적인 성공(이윤, 판매, } \\
\text { 시장 점유율) }\end{array}$ & 인지적인 성공 & $\begin{array}{c}\text { 활동적인 성공(스피드 } \\
\text { 생산성) }\end{array}$ \\
\hline
\end{tabular}


합리적 계획화 관점에서는 신제품 개발 팀과 상위 경영층(senior management), 그리고 시 장. 제품특성에 따른 기업의 재무적 성과에 대한 영향관계를 포괄적인 관점에서 제시하고 있고 문제해결의 관점에서는 실제적인 개발과정에서의 신제품 개발 팀과 팀에 대한 관리요 소를 중심으로 다루고 있다. 커뮤니케이션 웹 관점에서는 팀 내. 외부의 커뮤니케이션 측면 에서 연구를 하였다. 이러한 연구들은 신제품 개발문제에 대하여 인지논리(cognitive theory)적 시각과 정보의 양과 다양성, 그리고 정치적 측면을 부각하면서 자원의 중요성을 강조하고 있으나 신제품 개발의 성과 요인을 제시함에 있어 동어반복적인(tautological) 모호한 개념들(' 미묘한 통제(subtle control)', '제품 비젼(vision)', '시스템 중심')을 사용함으로써 현실적인 측면이 부족한 규범적인 연구라는 한계를 가지고 있다(Brown \& Eisenhardt, 1995). 또한 자원으로서 중요한 지식에 대한 인식과 지식 활용으로서의 신제품 개발 과정에 대한 초점이 부족하다.

2.2 새로운 접근법의 제시: 지식 체화(knowledge embodiment)의 관점

경쟁우위의 원천은 기업이 경쟁우위를 확보하고 이를 유지함으로써 경제적인 렌트 (economic rent)를 발생시킬 수 있는 것을 말한다(Schendel 1996). 구조-행위-성과의 패러다임에 근거한 불완전한 시장구조의 형성이나 시장 구조를 형성하고 있는 구동력(forces)의 상황이 경쟁우위 원천으로 작용한다는 주장(경쟁적 시장구조이론; Porter, 1980)이나 경쟁기업과의 불 균형성을 유지하는 것이 경쟁우위 원천임을 지적하는 연구(전략 갈등 이론; Ghemawat, 1986; Shapiro, 1989)의 경우 모두 특권화된(privileged) 제품 시장에서의 기업 지위로부터 경쟁우위 가 발생된다고 설명하고 있다. 그러나 최근에 기업 수준의 효율성 원리에 입각하여 기업의 내적인 요소에 초점을 맞춘 경쟁우위 원천을 설명하려는 흐름이 등장하고 있으며 이러한 연 구의 흐름은 기업 특정적 능력(firm specific capabilities)과 자원이 기업 성과에 대한 기본적인 결정 요소임을 지적하면서 능력과 자원을 결합하기 위한 기업의 독자적인 메카니즘(isolating mechanism)의 형성을 강조하고 있다(Rumelt, 1984; Teece, 1984; Wenerfelt; 1984; Dosi, Teece \& Winter ,1989; Prahalad \& Hamel, 1990; Dierickx \& Cool , 1989; Porter, 1990).

자원거점의 견해에서는 기업을 특이한 자원과 능력의 독특한 결집체(unique bundle)로 인 식하고 경쟁 전략을 수행함에 있어 중요한 과업은 자원과 능력을 최적으로 전개하여 가치를 극대화하고 기업이 필요로 하는 미래의 자원베이스로 발전시키는 것이라고 주장한다(Barney, 1991). 기업이 경쟁우위를 가지고 이를 유지할 수 있는 것은 이를 가능하게 하는 자원과 이 
러한 자원을 활용하는 체화된(embodied) 메카니즘을 가지고 있기 때문에 가능하다는 것이다 (Grant, 1996). 자원들이 상호 결합되어 기업의 핵심역량(core competence; Prahalad \& Hamel, 1990)을 형성하고 핵심역량은 경쟁 기업으로부터 모방되거나 이전되지 않아야 지속적인 경 쟁우위로서 작용할 수 있게 된다는 점을 강조하고 있다(Klein et al. 1978; Amit \& Shoemaker, 1993; Peteraf, 1993; Lippman \& Rumelt, 1982; Dierickx \& Cool, 1989; Barney, 1991). 최근에는 기업 이 보유하고 있는 자원 중 지식자원의 중요성이 강조된다(Conner 1991; Kogut \& Zander 1992,1996; Conner \& Prahalad,1996).

기업의 내적 자원과 진화론적 관점을 포괄한 역동적 능력(dynamic capability)관점에서는 기업 특정적 능력(firm specific capabilities)의 차원을 정의하고 역량과 자원의 결합이 어떻게 개발, 전개되어 시간 차원의 흐름에 따라 어떻게 보호될 수 있는 가를 설명하고 있다. 이때 기업의 역동적인 능력은 기업 역량(핵심역량)으로 인식되며 이러한 역량의 결과물로서 기업 능력이 생성되는 것으로 파악하고 있는 것이다(Dosi, Teece \& Winter, 1989; Prahalad \& Hamel, 1990; Hayes \& Wheelwright, 1984; Dierickx \& Cool, 1989). 그러므로 기업의 경쟁우위 원천에 대 한 새로운 관점하에서 보면 신제품 성공요인에 대한 과거 연구들은 자원으로서의 지식에 대 한 인식과 지식의 획득과 활용과정이 신제품 개발 과정이라는 인식이 부족하다고 할 수 있 다.

신제품 개발과정에서는 다양한 시장지식과 기술지식이 필요하고 이러한 지식을 수용. 축 적. 활용하는 학습(learning)과정이 개발 과정의 효율성과 효과성에 영향을 미친다. 신제품 개발에 있어서 기업 역량은 고객과 경쟁자에 대한 지식을 수용/공유하고 이를 기술적인 지 식과 결합하는 것이라는 주장도 있다(Drucker, 1985). 기업은 신제품 개발과정에서 필요한 많 은 기술적인 지식, 시장지식을 획득하여 기업 내 기존의 지식과 결합함으로써 새로운 지식 을 창출하고 이를 제품으로 형성화시키는 것이다.

신제품 개발 과정에서는 개별적인 개인이 효율적으로는 보유하기 힘든 집합적인 (collective) 지식이 요구되기 때문에 팀(team)을 형성하는 것이 일반적이다. 그러나 팀이 형성 된다고 해도 잠재적으로 가능성이 존재한다는 것이지 집합적인 지식이 형성되는 것은 아니 다. 신제품 개발팀은 필요한 지식을 획득, 활용하는 능력을 통하여 새로운 지식을 창출하고 이러한 과정이 신제품 개발 팀 내에 배태됨(embedded)으로써 유효한 신제품 개발 수단으로 서 신제품 개발팀이 되는 것이다.

신제품의 개발과정에서는 경쟁 기업, 고객 욕구, 고객 욕구와 시장 수요의 차이(gap)를 1999. 9 
충족시키는 기술등에 관한 지식이 필요하고 이러한 지식은 명시적인 혹은 암묵적인 형태로 존재한다. 기업은 신제품 개발과정에서 명시적. 암묵적인 지식들을 획득, 공유. 확산 통합 하는 과정을 통하여 새로운 지식을 창출하고 창출된 지식을 구체적인 제품으로 전환하는 것 이 필요하다. 지식의 구체화(embodied)과정이 신제품 개발 과정인 것이다.

신제품 개발 과정에서 발휘되는 기업(혹은 팀)의 종합적인 능력을 지식역량(knowledge competence)으로 정의하고자 한다. 기업이 보유하고 있는 지식의 양과 수준(품질) 그리고 이 러한 지식을 활용하는 과정으로서의 역량인 지식 역량에 따라 신제품의 경쟁우위가 발생하 게 되는 것이다. 시장에서의 소비자의 욕구와 시장 수요간에는 차이(gap)가 있으며 욕구를 시장 수요로 전환하기 위해서는 기술적 가능성이 필요한 것이다. 시장 수요에 대한 고려가 없는 완전한 기술구동에 의한 신제품개발의 성공 가능성은 낮으며 그 반대의 경우는 제품으 로의 구체화가 어렵다. 소비자 욕구를 파악하고 기술적인 가능성을 타진하여 사업의 기회를 파악한다는 측면에서 신제품 개발은 시장지식과 기술지식을 사용함으로써 가능하며 이 두 지식의 통합에 의하여 제품으로 체화되는 것이다(Mahadvan, et al., 1998).

이러한 견해는 조직을 학습의 실체로 인식하는 조직학습 연구나 독특한 지식의 결집체로 조직을 인식하는 지식 거점의 관점과 일치한다.

신제품개발에 관한 최근의 연구에서는 신제품개발과정이 학습과정이며 학습의 효율적인 측면을 부각하고 있다(eg; Adams, Day, \& Dougherty, 1998; Ottum \& Moore, 1997; Methe, Toyama, \& Miyabe, 1997; Moorman \& Miner, 1997; Song, Souder, \& Dyer, 1997; Madhavan R. \& R. Grover, 1998; Li Tiger \& Calantone, 1998). 그러나 시장지식의 측면에 제한되어 마케팅정보처리 (marketing information processing)과정을 학습과정과 동일시하고 지식활용의 측면보다는 지식 보유에 초점을 맞추는 한계를 가지고 있다.

\section{3. 지식역량(knowledge competence)의 이론적 기반}

\section{1 지식과 지식역량}

${ }^{3}$ 전통적으로 혁신의 원천이 기술에 의한 것인가(technol ogy push)? 혹은 시장의 수요에 의한 것인가( market pull) 에 대한 논란이 있어 왔으나 기업의 신제품개발을 통한 혁신은 두 가지 측면이 상호 작용하는 것으로 인식되 어져야 한다(Price, 1996). 
Nelson \& Winter(1982)의 경우 지식을 문제해결(problem solving)을 위한 정보 투입물, 기존 지식, 그리고 능력(capability)의 집합을 전체적인 기업의 지식베이스가 되는 것으로 정의하고 있으나 본 연구에서는 지식(knowledge)과 지식역량(knowledge competence) 개념을 구분하여 인식한다. 지식을 시장, 경쟁 기업, 기술에 대한 조직화(organized)되고 구조화된(structured) 정 보의 의미로 파악하며 조직화는 무작위적인 추출과는 다른 체계적인(systematic)과정의 결과 물로서, 구조화는 무관계한 자료들이 분산된 형태가 아니라 유용한 의미를 주는 것으로 파 악한다.

지식을 '무엇이 옳은가(What is right)' 보다는 '어떤 효과가 있는가 또는 더 효과적인가 (What works or works better)'의 측면에서 바람직한 성과를 발생시키는 능력을 가지고 있는 목 적적인 의미로서의 지식이다. 효과성의 의미는 경쟁적인 맥락에서 이해되어져야 하며 이는 상업적인 지식(commercial knowledge; Demarest, 1997) 또는 활동 능력(capacity to act; Sveiby, $1997, \mathrm{p} .37)$ 의 의미와 통한다.

정보와 지식의 구별이 명확하지 않은 이유는 지식의 유기체적인 성향으로 인한 자기 조 직성 때문이며 지식 형성은 외부로부터 자료나 정보를 받아들여 기존 지식과 결합하고 또 다른 의미있는 지식으로 조직화하는 과정에서 이루어진다. 결국 지식은 정보로 전환되고 정 보는 지식으로 전환되는 과정이 반복되어지는 것이다.

전통적인 노동, 자본, 토지의 생산요소에서 지식이 제 4 의 생산요소로서 인식되고 (Drucker, 1993; Spender, 1996) 자원으로서 중요한 지식을 가지고 있는 것만으로 경쟁우위를 발생시키지 않으며 지식이 가지는 정보적인 특성 ${ }^{4}$ 으로 인하여 기업특유의 지식(사유재; private goods)으로 전환하는 기업의 능력이 필요하다(Spender, 1996). 기업 특유의 지식으로 전 환하는 기업 능력이 지식역량이며 지식역량을 발휘하는 과정에서 지식의 수용. 활용. 축적 이 이루어지는 것이다.

역량(competence)은 과정의 연속이다. Day(1994, p.38)는 조직적 과정을 통하여 발휘되는 복 잡한 기능의 결집이나 집합적인 학습(collective learning)으로 역량을 정의하며 Prahalad \& Hamel(1990)은 핵심 역량을 기업과 시장의 상호작용, 기업내 기능간 통합 과정으로 정의하 면서 조직의 핵심능력을 구현할 수 있는 것이 지식이라고 하였다.

본 연구에서의 지식역량(knowledge competence)은 필요한 지식을 창출하고 통합하는 과정

\footnotetext{
기존 지식의 손실없이 재판매가 가능한 공공재(public goods)적인 성격(Arrow, 1984)으로 인하여 지식 소유의 경계가 불분명하여 모방이 쉽게 발생한다. 그러므로 기업은 전용가능성(approapriability)을 위하여 지적 재산권 보호나 지식의 암묵성을 높이려고 한다.

1999. 9

신제품 개발조직의 지식역량 향상 53
} 
에서 발휘되는 기업의 동태적 능력(dynamic capability)을 의미한다. 과정(process)의 의미는 활 동의 연속이며 '축적(stock)'된 지식과는 달리 이러한 지식의 축적을 가능하게 하는 과정의 집합을 의미하는 것으로 파악한다. 지식 창출은 필요한 지식을 조직 내로 수용하고 이를 이 용하는 과정에서 지식 역량에 의하여 새로운 지식으로 확장된다.

\section{2 지식 역량의 구성 요소}

조직학습은 의사결정에 필요한 관련 지식을 획득, 커뮤니케이션, 해석하는 시스템을 의미 하고 주관적인 개인 지식을 객관화하거나 개인 지식을 조직의 지식 베이스로 만드는 것이며 조직학습에 의한 결과는 공유되고 행동과 결과의 휴리스틱적 평가과정을 통하여 통합되어 하나의 시스템으로 구조화된다. 즉, 조직학습은 정보 공유, 계획화 등을 통제, 관리하는 공식 적, 비공식적 메카니즘을 포함하는 학습시스템으로 제도화된다(Shrivastava, 1983).

행동 변화에 대한 지식의 영향력은 지식활용 문제와 관련된다(Nonaka, 1990). 정보 획득, 확산, 공유된 해석(shared interpretation; Sinkula, 1994)과정을 통하여 이루어지는 조직 학습과정 에서 정보 획득은 직접적인 경험, 모방, 또는 조직 기억의 검색으로부터 획득되며 효과적인 확산/공유를 통한 정보 사용은 조직 구성원들에 의해 해석되고 새로운 통찰력을 제공할 수 있도록 피드백(feedback) 혹은 확대/수정됨으로써 정보로서의 가치가 증가한다(Glazer, 1991; Quinn, 1992). 효율적인 신제품 개발을 위하여 기업 내 관련 기능들이 상호작용(interface)하는 것이 중요하며(Gupta, Raj, \& Wilemon, 1986, p.7) 효과적인 상호작용은 다기능적인(cross functional) 활동과 토론 그리고 정보의 교환을 통하여 이루어진다(Cooper \& Kleinschmidt, 1991.p.140). 기능간 정보 교환의 장벽을 제거하여 의사결정이 신속하게 이루어지고 정보가 효과적으로 사용됨으로써 지식역량이 향상될 수 있는 것이다.

조직학습의 마지막 단계로서의 정보에 대한 공유된 해석은 조직 내 갈등을 해결하기 위 한 불일치 요인을 표면화시키는 구조적인 과정과 정보 공유나 의사소통 흐름을 제한하는 것 을 제거할 수 있는 집단 규범을 개발하는 것과 관련되어 있다(Slater \& Narver, 1995).

과정의 연속으로서의 지식역량은 지식 창출 과정이 조직의 인지적인 활동 내에 배태되어 져 있어 외부로부터의 관찰이 즉각적이지 않고(비모방성(inimmitableness): Day, 1994; Prahalad \& Hamel, 1990) 기업 내에서 창조되기 때문에 시장에서 구입하기 힘든 비이동성(immobility) 을 가지고 있다(Day, 1994). 또한 시간에 따라 가치가 소멸되는 기계와는 달리 시간이 지나도 
가치가 소멸하지 않는 비소멸성(undiminishableness: Prahalad \& Hamel, 1990)을 가져 지속적인 경쟁우위의 조건이 된다.

본 연구에서는 지식역량을 외부지식을 획득하는 수용능력(receptive capacity), 상호 이질 적인 지식을 조합하는 능력(combination capacity), 지식 조합 과정에서 발생하는 상호의존성을 조정하는 능력(coordination capacity), 지식 획득과 사용에 있어 시간적인 차이(gap)를 해결하 는 유지· 변환하는 능력(maintenance· transformative capacity)으로 구분한다. 이러한 능력들의 순환 과정이 지식역량으로 형성된다.

[그림 1] 지식 역량의 구성 개념

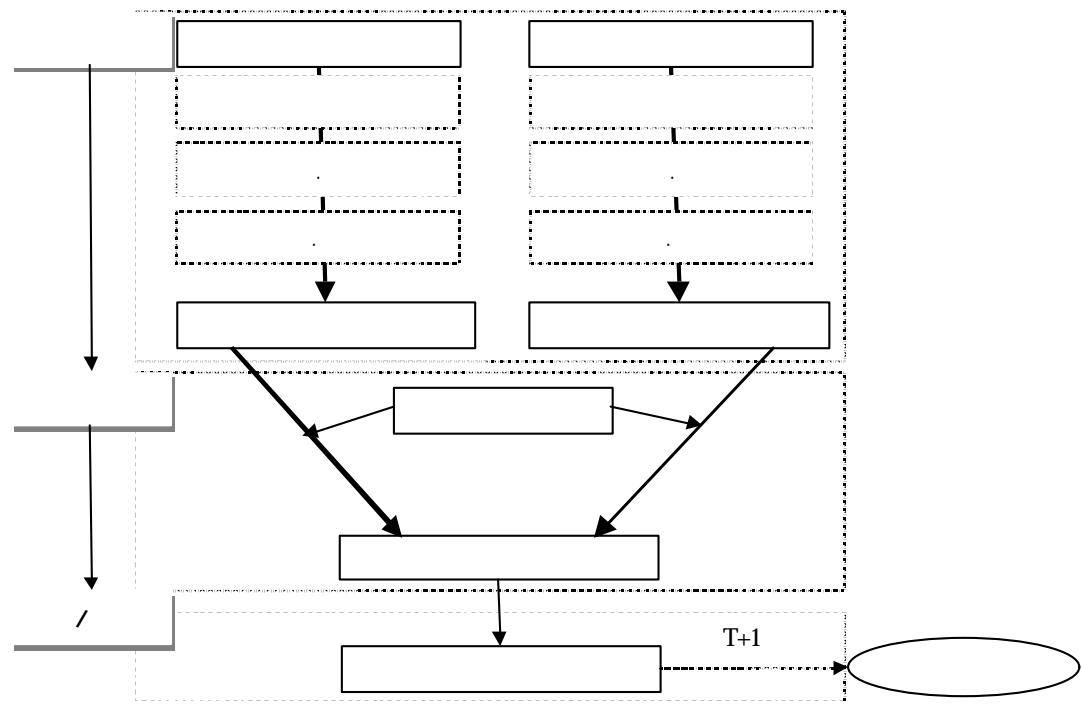

\section{4. 신제품 개발과정에서의 지식역량}

\section{1 수용능력(receptive capacity)과 신제품 개발}

지식을 수용하는 과정에서는 지식 자체가 내포하고 있는 특성-무형성(intangibility)과 암묵 성, 복잡성, 지식(특히 기술)의 격변성-으로 인하여 지식 수용의 불확실성이 발생한다. 무형 성(intangibility) 혹은 암묵성의 특성은 거래에 필요한 단위나 가격이 산정되기 힘들고 지식 
의 비대칭적 사용이 기업의 경쟁우위를 가져오기 때문에 지식을 보유하고 있는 기업은 외부 기업으로부터 보유하고 있는 지식에 대한 접근을 제한하려고 한다.

[표 3] 지식 수용상의 불확실성

\begin{tabular}{|c|c|}
\hline 지식의 특성 & 지식 수용상의 위험요인 \\
\hline 무형성 & 거래단위의 설정 $\cdot \quad$ 가치평가 문제(정보가치의 모호성) \\
\hline 암묵성 & 부호화 문제 \\
\hline 복잡성 & 이해와 학습의 문제 \\
\hline 격변성 & 경로의존성 또는 누적성의 문제 \\
\hline
\end{tabular}

또한 지식을 보유하고 있는 기업과 보유하고 있지 못한 기업간 정보 불균형(information impactedness)은 숨겨진 정보(hidden information)와 숨겨진 행동(hidden action)의 대리인 문제도 발생시킨다(Arrow, 1985; Bergen et al, 1992) ${ }^{5}$. 그러므로 지식 전달의 효과적인 지배 구조를 선 택하거나 지식 수용에 따르는 성과에 대한 평가와 보상(incentive), 전달과정에서의 커뮤니케 이션 품질을 높여 불확실성을 해결하려고 하지만 기업의 제한된 합리성으로 인하여 완전하 게 해결되지는 않는다. 그러므로 외부로부터 지식 수용에는 불완전한 계약(incomplete contract)과 이에 따른 높은 거래 비용이 발생된다.6.

결론적으로 거래 대상으로서 지식이 가지는 특성 때문에 지식 수용의 장벽이 생기고 (Reed \& DeFillipi, 1990; Baradwaj, Varadarajan, \& Fahy, 1993) 불확실성에 따르는 이전 장벽의 제 거, 지식 이전에 따르는 거래비용을 줄일 수 있는 능력이 수용능력이다. 수용능력은 접근 능 력과 이전 능력을 포함하는 개념이다.

[표 4] 지식 수용 능력

\begin{tabular}{|l|c|c|}
\hline 수용능력 & 세부 능력 & 내용 \\
\hline \multirow{2}{*}{ 접근 능력 } & 탐색능력 & · 지식의 위치(locus)파악 · 지속적인 모니터링 \\
\cline { 2 - 4 } & 네트워킹능력 & · 지식간 네트워크 형성 · 기존 네트워크에 접근 \\
\hline 이전 능력 & 여과(filtering) 능력 & · 정보 가치 평가 · 중요 정보 우선 순위 결정 \\
\hline
\end{tabular}

숨겨진 정보 문제는 지식 수용에 필요한 정보를 정확하게 갖고 있지 않기 때문에 발생하고 숨겨진 행동의 문제는 지식 전달 기업이 약속한 바대로 지식을 이전하는 가의 문제이다.

6 계약과 관련한 비용(계약비용), 계약 이후 발생하는 조정비용(Gurbaxani \& Whang, 1991) 지식의 정확성을 검증하는 검증비용(Huber, 1982), 잔존손실, 모니터링 혹은 이해 부족에서 발생하는 기회비용도 존재한다(Choudhury \& Sampl er, 1997). 그 외에도 탐색비용, 저장비용, 정보이전비용( i nf or mat i on transmi ssi on cost) 등이 있다.

1999. 9 


\begin{tabular}{|c|c|l|}
\hline \multirow{2}{*}{} & 커뮤니케이션 능력 & $\begin{array}{l}\text { · 커뮤니케이션품질(정확성,시간 적절성,적합성) 증대 } \\
\text { 정보모호성을 극소화 }\end{array}$ \\
\cline { 2 - 3 } & 신뢰구축능력 & $\cdot$ 신뢰를 통한 대리인 문제 해결 능력 \\
\hline
\end{tabular}

외부지식에 대한 접근능력은 탐색(scanning)능력과 네트워크를 형성, 또는 기존 네트워크 에 진입할 수 있는 네트워킹 능력을 의미한다. 탐색 능력은 조직 외부에 존재하는 중요한 지 식의 위치(locus)를 파악하고 지속적으로 모니터링(monitoring)하는 능력이다. 탐색 능력으로 인하여 신제품 개발과정에서 필요한 지식의 방향성을 파악하고 필요한 지식을 내부로 이전 하는 시간을 절약한다. 특히 신제품이 호환성이나 네트워크 외부성(network externality)을 가지 는 커뮤니케이션 제품(communication goods)인 경우 표준화가 신제품의 시장 진입이나 경쟁우 위의 확보와 직결된다. 기술지식뿐만 아니라 고객/시장에 대한 지식을 획득하기 위해서도 네 트워크가 중요한데 고객과의 지속적인 관계와 신제품 개발과정에 고객이 참여함으로써 신제 품 개발 성과를 높일 수 있다(von Hippel, 1982).

접근되어진 지식을 조직 내부로 이전하는 경우 지식을 여과(filtering)하는 능력과 지식 전달자와 커뮤니케이션을 원활하는 능력, 기회주의적 행동을 억제하는 신뢰(trust)를 구축하 는 것이 필요하다.

여과 능력은 정보로서 가치를 가지고 있는 중요한 지식인가?를 파악하여 가치에 따라 이 전의 순위를 결정하는 능력이다. 또한 부호화가 어려운 암묵적인 지식은 특정 부호(예: 언어, 문서 등)로 전환되어야 하고 이를 쉽게 이해하기 위해서는 이해의 기반(공통 언어/공통 영 역)이 필요하다(Aoki, 1990; Mody, 1993). 지식의 효과적인 수용을 위한 '고용' 이나 '실행에 의 한 학습(learning by doing)'이 지식 수용의 좋은 방법으로 제시되는 이유는 정보 모호성을 극 복할 수 있는 이해의 기반의 확보가 용이하고 커뮤니케이션의 품질이 높기 때문이다.

개발되는 신제품이 신기술에 의존하는 경우 필요한 신기술의 기술적인 능력에 대한 신빙 성(상품화 가능성)에 대한 불확실성 때문에 약속된 성과에 대한 확신이나 평가를 어렵게 하 고 지식의 수용과정에 대한 몰입을 요구하게 된다(Heide \& Weiss, 1995). 특히 신기술에 의한 신제품 개발과정에서는 정보의 비대칭성 문제가 발생할 가능성이 높아 이러한 문제의 해결 을 위해서는 반복적인 설명과 빈번한 비공식적 커뮤니케이션, 쌍방의 신뢰가 중요한 역할을 한다(eg: Madhok, 1995; Chiles \& McMackin, 1996). 신뢰는 기회주의적인 행동을 억제하고 상호 간의 신뢰가 진화되면서 상호 행동의 예측 가능성을 높이는 관계 규범으로 발전하게 된다 (Brusco, 1982; Axerlod, 1984; Weitz \& Zap, 1995). 
4.2 조합능력(combination capacity)과 신제품 개발

독창성과 새로운 아이디어는 다양한 지식 집합들의 상호작용에서 비롯된다는 명제는 지 식 관련 연구(Simon, 1985), 사회 네트워크에 관한 연구(eg; Granovetter, 1973) 그리고 복잡성 (complexity) 연구에서 지적되고 있다.

신제품 개발에 필요한 다양한 지식의 상호작용은 신제품 개발 팀내의 구성원들간 지식의 공유과정에서 발생한다. 또한 개인적인 수준에서만 지식의 상호 작용이 일어나는 경우 개인 이 조직을 이탈함으로써 조직 내 지식이 상실되기 때문에 개인지식을 조직 지식으로 전환하 는 작업이 필요하다. 이것이 지식 조합 능력이다.

[그림 2] 지식의 조합 과정

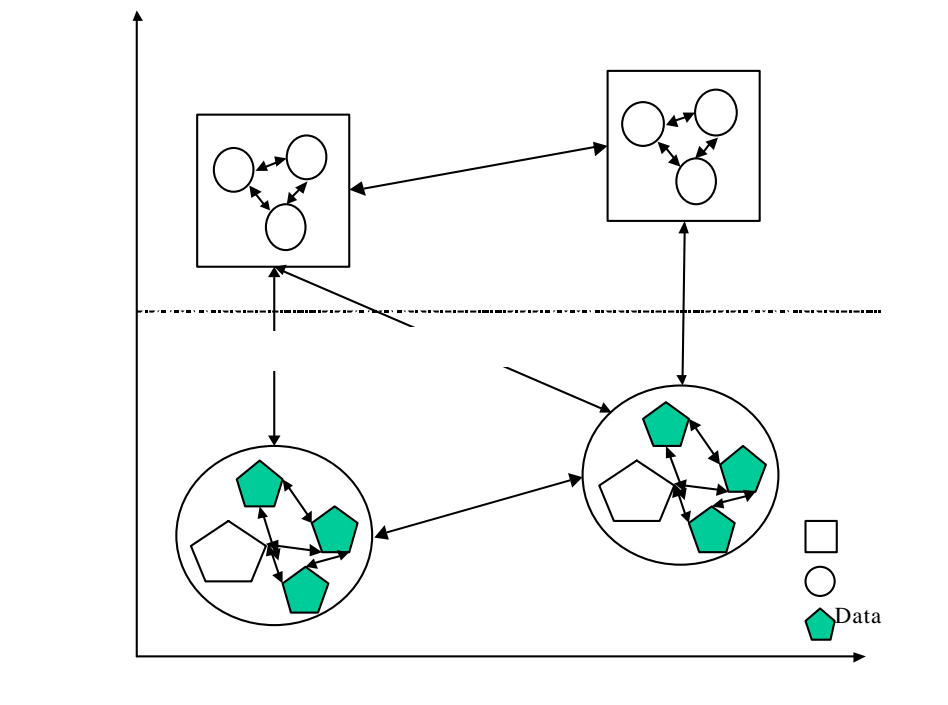

지식의 조합과정은 조직 내에서 지식이 공유. 확산되는 과정을 통하여 이루어지는데 이 러한 과정은 개인 혹은 조직 수준내(in-level)에서 이루어지고 또한 개인-조직간(cross-level) 이루어지게 된다.

수준 내에서 발생하는 공유- 확산과정은 형상화(articulation)와 내부화(internalization)를 통 하여 이루어지는데 형상화는 암묵적인 지식을 명시적인 지식으로 전환하는 것을 의미하며 내부화의 경우는 그 반대의 과정을 의미한다(Hedlund, 1994). 개인적 수준에서의 내부화는 개 
인이 보유하고 있는 개별 지식을 조합하여 개념화하는 것으로 오랜 경험에 의하여 숙련되어 지는 기능(skill)이 그 예이다. 조직 수준에서도 구성원의 분산된 지식을 체계화하는 조직 활 동을 루틴화(routinize)할 수 있다. 형상화 과정에 의하여 지식의 탐색. 심사가 가능하고 지 식을 확장하는데 중요한 역할을 한다. 형상화 과정이 없다면 조직 내 새로운 구성원의 참여 나 과업의 분화, 전문화를 유지하기 어렵다. 기업이 개발하여 시장화하는 신제품은 신제품 개발 팀의 지식을 제품으로 구체화(embodiment)시키는 과정이므로 지식 형상화를 통하여 지 식의 상호 작용이 가능해 진다(Lynn, 1998; Madhavan, et al., 1998). 지식의 형상화 과정에서 활 동 지향적인 측면에서 지식 사용이 이루어지고 형상화와 내부화의 상호작용이 '반영 (reflection)' 과정이며 새로운 지식 창출과정에서 상당히 중요한 역할을 한다(Nonaka, 1987; Hedlund, 1994).

수준간(cross-level) 공유. 확산과정은 확장(expansion)과 전용화(appropriation)를 통하여 이 루어진다([그림 2] 참고). 확장은 개인 지식을 집단(team) 지식으로 명시적 혹은 암묵적인 형 태로 전환하는 것이며 신제품 개발팀을 구성하는 이유도 개인들의 분리된 지식을 상호 공유 함으로써 집단지식으로 전환하는 과정이 된다(Madhavan \& Grover, 1998).

신제품 개발 팀은 고립되어있는(solitary) 개인이 소유하고 있는 것 보다 더 많은 것을 가 지며 개별적인 지식의 상호작용을 유도하고 이로써 인지적인 성과를 포함한 팀 성과가 달성 된다(Patel, Kaufman \& Madger, 1996 p.140). 신제품 개발팀을 분산된 인지 개념으로 인식하여 분리된 개별적인 팀 구성원들의 조정된(well-coordinated) 집단으로 인식하는 경우 개인 지식 을 집단지식(collective knowledge; Spender, 1996)으로 확장하는 것이 요구된다.

전용화의 과정은 확장과는 반대로서 집단 지식을 개인 수준의 지식으로 전환하는 과정으 로 신제품과 관련된 지식을 명시적으로 가르치거나 혹은 신제품 개발 조직의 암묵적인 지 식을 주입하는 것도 포함한다.

확장과 전용화의 상호작용이 '대화(dialogue)'의 과정이다(Hedlund, 1994). 신제품 개발 과정 에서의 지식 공유. 확산 과정은 '반영' 과 '대화' 의 과정이며 대화와 반영의 양과 질이 지식 창출의 형태와 효과성을 결정하는 중요한 요소가 된다(Hedlund, 1994). 그러므로 지식 조합 능력은 확장과 전용화의 상호작용(대화:dialogue)과 암묵적 지식과 명시적 지식의 상호작용 (반영:reflection)을 원활히 수행하여 개별적 지식벡터(knowledge vector)를 교차/결합하는 능력 으로 정의한다. 신제품 개발과정에서 시장 탐색, 개념 개발, 시장 정의/개발등의 마케팅 과 정과 기술적 가능성 탐색, 원형 개발과 테스팅, 효율적인 생산 방식 검토 등의 기술적인 과 
정이 동시에 이루어진다. 이 과정에서 신제품 개발에 필요한 시장 지식과 기술지식이 공유 되며 공유과정은 신제품 개발팀 구성원의 상호 작용을 통하여 이루어진다.

신제품 개발조직 구성원의 공통 지식(공유된 정신 모델:shared mental model)의 보유, 빈번 한 개인간 접촉, 정보 중첩성(redundancy)이 조합능력을 향상시키는 조건이다(Grant, 1996; Madhavan \& Grover,1998; Mody, 1993, Nonaka, 1990). 공통 지식은 '반영'과 '대화'의 과정에서 발 생할 가능성이 있는 지식의 손실을 최소화한다. 상호 작용하는 당사자들이 보유한 지식과 사전에 공유된 의미가 중첩된 정도가 의사소통의 유형과 질을 결정한다(Grant, 1996; Nonaka \& Takeuchi, 1995, pp. 80-81). 빈번한 개인적 상호작용은 직접적이고 비공식적인 의사소통이며 물리적인 근접성보다는 직접적인 접촉을 통한 '이면에서 제공되는 메시지(messages transmitted in the back channel: Yngve, 1970)'가 의사소통의 효과성을 높일 수 있고(Pinto, Pinto, \& Prescott, 1993 ) 접촉이 간헐적으로 이루어지면 지식을 내부화하기 위한 충분한 기회가 되지 못할 수 있다(Hudlund \& Nonaka, 1993). 전통적인 정보처리 모델에서 주장하는 공식 절차나 정의된 역 할보다는 사회적인 연계(link)가 정보 흐름에 더욱 중요하며 혁신을 유도하는 적합한 방법이 다(Meyers \& Wilemon, 1989; Mezias \& Glynn, 1993).

[표 5] 지식 조합능력 향상의 조건

\begin{tabular}{|c|l|l|}
\hline 조건 & \multicolumn{1}{|c|}{ 내용 } & \multicolumn{1}{|c|}{ 연구자 } \\
\hline $\begin{array}{c}\text { 공통된 } \\
\text { 지식 }\end{array}$ & $\begin{array}{l}\text { · 공통의 언어 · 유사한 상징적 의 } \\
\text { 사소통 · 공통의 의미 }\end{array}$ & Grant, 1996; Nonaka \& Takeuchi, 1995 \\
\hline $\begin{array}{c}\text { 개인적 } \\
\text { 접촉 }\end{array}$ & 상호작용성 · 반복성 - 비공식성 & $\begin{array}{l}\text { Hudlund \& Nonaka, 1993; Meyers \& } \\
\text { Wilemon, 1989; Mezias \& Glynn, 1993 }\end{array}$ \\
\hline $\begin{array}{c}\text { 정보의 } \\
\text { 중첩 }\end{array}$ & $\begin{array}{l}\text { 훙부한 정보 · 정보과부하의 문제 } \\
\text { 혈 }\end{array}$ & $\begin{array}{l}\text { Teece, 1998; Madhavan \& Grover, } \\
1998\end{array}$ \\
\hline
\end{tabular}

정보의 중첩성이란 필요한 최소한의 정보보다 더 많은 정보가 공유되는 것을 의미한다. 심리학에서는 개인이 새로운 정보를 이해하는 능력은 기존 지식을 범주화하고 이들을 연결할 수 있는 능력과 관련이 있음을 지적하고 있다(Bower \& Hilgard, 1981). 지식을 범주화하는 것은 개인 특정적이기 때문에 동일한 정보를 다른 의미로 받아들일 가능성이 존재한다. 이러한 측 면에서 중첩된 정보가 혁신의 원천이 되는 사람과 아이디어의 상호작용을 부추기는 좋은 방 법이 된다는 것이다(Mezias \& Glynn, 1993; Nonaka, 1990). 전통적인 연구에서는 정보 과부하 (Rogers \& Rogers, 1976)나 정보 이해능력의 부족으로 인하여 정보 가치를 인식하지 못하는 
위험성이 존재하는 경우 정보통제자(information gate-keeper)의 역할을 강조하고 있으나 정보 통제자의 역할이 지나치게 강조되는 경우 정보의 중첩을 통한 새로운 발견, 우연한 창조의 이점을 상실하게 된다(Mahadvan, et al, 1998; Teece, 1998; Mahadvan, et al, 1998).

\section{3 조정능력(coordination capacity)과 신제품 개발}

Grant(1996)는 조직의 능력을 지식 통합의 결과로 보고 복잡하고 팀에 근거한 생산적인 활동(예: 신제품 디자인 과정)은 개별적인 지식을 가진 전문가를 어떻게 결속하고 통합하는 가에 달려있다고 주장하였다. 통합능력의 특이성이 조직능력의 특이성을 가져오는 것임을 강조하고 있는 것이다. 그러나 Grant 가 제시한 조직 능력으로서의 통합능력은 상호 이질적 인 지식을 결합하는 지능적인 측면에서의 조합능력(combination capacity)과 지식을 가진 개인 이나 기능부문들간의 이해나 목적을 조정하는 사회적인 기능으로서의 조정능력(coordination capacity)을 포함하는 개념이다.

신제품 개발과정과 관련한 문헌에서는 통합(integration)의 의미를 '다기능적인 연결(crossfunctional linkage)'과 '협력(collaboration)'의 의미를 가지는 것으로 인식하고 이를 상호 교환적 으로 사용하고 있다(Jassawalla \& Sashittal, 1998). 지식을 통합하거나 기술적인 상쇄관계로 인 한 혼란을 해결함에 있어 조정능력은 중요하다. 신제품 개발과정에서 다양한 기능 부서들간 (R\&D-생산-마케팅) 협력을 통한 시너지 효과가 중요함에도 불구하고 기능 부서간 추구하는 목표(goal)가 달라 협력이 쉽게 이루어지지 않는다(eg; Song \& Parry, 1993; Gupta \& Wilemon, 1988; Lilien \& Yoon, 1989; 임 종원 \& 김 기찬, 1989).

신제품 개발에서의 조정능력은 지식조합 과정에서 발생하는 상호의존성 때문에 발생하는 이해를 조정하는 사회적인 기능이다. 상쇄적인 관계를 관리함에 있어 가장 중요한 것은 신 뢰(trust)를 구축하는 것이다. 서로의 의도와 행동에 대한 신념(faith)으로서의 신뢰(Kreitner \& Kinicki, 1992)는 조직 내에서 뿐만 아니라 전략적 제휴나 JIT(Just in Time)과 같은 사회적인 관계에서도 많이 언급되어 왔다(eg; Zand, 1972, 1981).

조정능력으로서의 신뢰는 조직(혹은 팀)지향성에 대한 신뢰와 구성원들의 지식에 대한 신뢰로 구분될 수 있다. 조직(혹은 팀)지향성의 경우는 개인적 또는 부서의 목적보다 팀의 목적에 따라 행동하려는 의도를 가지고 있다고 상호간 믿는 정도를 의미하며 구성원의 지식 
에 대한 신뢰는 지식을 통한 문제 해결능력에 대한 신뢰 즉, 지식의 신빙성을 의미한다 (Mahadvan \& Grover, 1998).

팀 지향성에 대한 신뢰가 부족한 경우, 정보를 유보하거나 조직의 자원을 좁은 이해관계 나 팀의 목적과는 다르게 분산시킬 위험이 존재하며(Zand, 1981) 신뢰 부족에 의한 정보의 유보는 지식 축적, 혹은 지식의 내부화 형상화의 상호작용에 부정적인 영향을 미쳐 기능간 팀(cross-functional)의 성과를 낮추는 요소이다(Hedlund \& Nonaka, 1993).

4.4 유지 · 변환능력(maintenance - transformative capacity)과 신제품 개발

지식 축적은 경로 의존적(path-dependent)이므로 지식이 필요한 필요한 시점에 즉각적으로 획득하거나 쉽게 대체하기도 힘들다. 문제해결 활동에 의하여 아이디어나 기법(techniques)이 나오며(Allen, 1966; Laudan, 1984; Rosenberg, 1982) 지식 개발은 이러한 아이디어나 기법의 축 적으로 이루어진다(Crane, 1972). 선행 지식은 향후 발생하는 문제의 선택에 영향을 미치고 지식개발을 경로 의존적으로 만든다(David, $1985 ;$ Dosi, 1982) . 지식을 활용하는데 지식개발 에 따르는 시간지체 혹은 시장에서의 시간지체가 발생하기 때문에 시간차원에서의 지식 이 전이 필요하고 향 후 사용될 지식을 유지하는 것이 중요한 문제가 된다.

시간의 흐름에 따른 지식 이전과 관련한 능력을 유지· 변환능력(Garud \& Nayyar, 1994)이 라 정의할 수 있다. 지식의 수용능력이 외부로부터 지식의 기회를 인식하고 활용하는 능력 이라고 하면 유지 변환능력은 기업 내에서 창출된 지식에 근거하여 제품 포트폴리오를 지 속적으로 재정의할 수 있는 능력이다. 기업 특정적인 지식이 되어버린 지식을 외부에서 수 용하려는 경우 지식의 경로 의존적, 누적적 특성으로 인하여 수용에 어려움이 존재하기 때 문에 지식의 유지 변환능력은 지식을 검색/평가하는데 상대적인 이점을 제공하며 시간의 흐름에 따라 지식 수용능력으로 전환되는 것이다. 그러므로 지식의 유용성과 정보의 가치를 평가, 이를 이해할 수 있기 위해서도 지식을 유지하고 조직 기억(organizational memory: Levitt \& March, 1988; Walsh \& Ungson, 1991)화하는 작업은 매우 유용한 것이다.

시간에 따른 지식의 유지 변환과정은 시간적인 차원(inter-temporal)에서의 지식 이전과정 이며 유지되어야 할 지식의 선택, 유지 그리고 재활성화와 합성(synthesis)의 과정을 거치게

\footnotetext{
${ }^{7}$ 이러한 관점에서 보면 기업의 재구조화(restructuring)는 지식의 축적을 파괴하고 재구조화 과정에서 새로운 지식을 획득하는데 필요한 시간 지체(time lag)가 발생하게 된다(Garud \& Nayyar, 1994).

8 시장에서의 시간 지체라 함은 제도적인 변화나 과학적, 기술적 진보로 인하여 고객에게 더 매력적인 제품이 나타나 신제품에 대한 수요가 향후에 나타날 수도 있기 때문에 부적당한 신제품의 수요로 인하여 많은 혁신들이 실패하는 경우를 말한다(Wilson \& Hlavacek, 1984).

1999. 9

신제품 개발조직의 지식역량 향상 62
} 
되며(Garud \& Nayyar, 1994) 지식이 정보 시스템이나 절차(procedure), 루틴과 같은 암묵적인 형태 혹은 청사진/문서와 같이 기록되거나 부호화된 명시적인 형태로서(Foster, 1971; Slater \& Narver, 1995) 조직 기억화되어 구성원 이직(turnover)등에 의한 지식의 상실을 막는 역할을 한다(Slater \& Narver, 1995; Walsh \& Ungson, 1991).

필요한 보완적 지식이 부족한 상황을 피하기 위해 점화수준 이상의 지식을 유지하는 것 도 중요하다(Garud \& Nayyar, 1994). 지식 유지에 따른 지식 이용가능성 자체가 지식 사용을 보장하는 것이 아니기 때문에 조직 기억 내에 보존되어 있는 지식의 사용은 검색을 통한 재 활성화와 합성의 과정이 수반되어져야 하고 격변하는 환경하에서는 신속한 검색을 통한 혁 신의 속도를 높이는 것도 중요하다(Garud \& Nayyar, 1994).

그러나 조직 기억에 의존한 기업의 전통적인 능력은 경쟁력의 함정(competence trap: Levitt $\&$ March, 1988) 혹은 핵심 경직성(core rigidity: Leonard-Barton, 1992)으로 작용하여 조직의 창조 적인 학습을 제한하거나 부적절한 학습을 유도할 수 있어(Dickson,1992) 지식의 유지. 변환 능력에 있어 기업의 능동적인 폐기학습(unlearning)과 위험을 감수할 수 있는 동기가 중요한 역할을 한다(Schein,1990,1993).

\section{5. 지식 역량 향상을 위한 전략적 관리}

신제품의 경쟁우위를 결정하는 지식역량을 향상시키기 위한 관리 노력은 어떻게 수행되 어야 하는가? 신제품 개발조직의 지식역량을 향상시키기 위한 관리 노력은 조직의 문화(분 위기) 측면, 구조적인 측면, 그리고 개발 팀 구성원의 측면에서 통합적으로 관리되어져야 한 다.

\section{1 신제품 개발조직의 문화: 학습의도의 개발}

신제품 개발과정에서의 구성원들의 학습의도(learning intent)가 기업의 학습욕구를 결정한 다(Hamel, 1991). Edmund \& Husserl(1968)의 주장처럼 그 자체로서의 의식(consciousness)보다는 대상에 주의를 기울이는 경우 의식이 발생하고 이는 대상에 대한 주체의 몰입에 따라 지속 되기 때문에 유기체로서의 인간이나 조직이 궁극적인 목적인 생존을 위한 환경으로부터 의 미 추출과 가치판단의 틀(frame)이 없이는 환경에 대한 의미를 얻기는 어렵다(Nonaka, 1994). 정보의 의미는 특정한 시스템이 목적하는 바와 시스템이 존재하는 상황에 따라 다르며 현재 
의 상황보다는 미래의 기대나 열망과 더 관련이 깊다. 환경에 대한 규정은 자기 충족적(selffulling)인 예상이며 자기활동(self-actualization)을 위한 강력한 의지의 반영이 되는 것이다 (Weick, 1979). 의도가 없다면 지각되거나 창출된 지식이나 정보의 가치를 판단하는 것이 불 가능하며 의도성은 의미의 가능성을 창출하고 형태에 대한 제한을 부가할 수 있는 것이다 (Searle, 1983, p.166; Nonaka, 1994).

구성원의 학습의도를 자극하기 위하여 창조된 불확실성(Mody, 1993)을 유지하는 것이 필 요하며 창조된 불확실성은 조직에 있어 하나의 긴장요인이 된다. 조직관성은 조직 경쟁력의 함정으로 작용하게 되며 불확실한 요인들이 존재함으로써 조직은 기존 루틴을 파괴하여 새 로운 규칙을 창출할 수 있는 것이다. 조직은 환경의 불확실성에서 만들어진 모호성, 중복, 소음, 무작위성에 대응하기 위하여 새로운 지식 시스템을 재창출한다. Nonaka(1994)도 지식 창출 기업의 요건의 하나로 상황변이(파동; fluctuation)를 제시하고 있는데 조직이 지속적으 로 학습을 통하여 지식역량을 향상시키고 이를 경쟁우위로 연결하기 위해서는 적절한 불확 실성을 창조하는 것이 필요하다. 기업의 혁신과정 혹은 신제품의 개발을 통한 새로운 시장 개발 활동들은 기업조직이 창출하는 불확실한 상황이 되는 것이다.

그러므로 신제품 개발조직은 구성원의 학습의도를 자극하는 조직 문화를 형성하여야 하 며 불확실성을 유지함으로써 전통적인 기업의 능력이 경쟁력의 함정으로 변하는 것을 막아 야 한다.

Proposition 1: 창조된 불확실성의 상황으로서의 신제품 개발과정에서 구성원의 학습의 도는 신제품 개발 조직의 지식역량을 향상시킨다.

5.2 신제품 개발조직의 구조: 유기적인 조직구조

학습의도가 학습욕구를 구성하는 것이라면 투명성(transparency)은 학습의 잠재력을 결정 하는 것이다(Hamel, 1991). 외부조직에 대한 개방성의 정도를 의미하는 투명성은 관리되어야 한다(Hamel, 1991). 기업이 지식역량을 확장하기 위해서 외부 조직과의 개방성이 유지되어져 야 하나 조직 내의 전용가능한 지식의 노출을 막아야 하는 측면도 존재한다. 지식공유의 역 설(paradox)이다. 그러므로 투명성은 디자인된 투명성이어야 한다. 즉, 지식역량을 확장하기 위한 조직의 개방성이 조직내의 지식에 대한 의도되지 않은 노출이나 예상되지 않았던 노출 을 억제하여야 한다. 
관리된 투명성은 신제품 개발에 필요한 보완적인 지식간의 연결(knowledge link)을 형성하 여 네트워크 집단을 구성하게 되며 네트워크내에서의 협력과 네트워크간의 경쟁이 이루어진 다. 그러나 네트워크가 고정되어 있기 보다는 활동이나 전략에 따라 유연성을 가지는 것이 중요하다. 유연성(flexibility)은 변화하는 환경에 대한 활동, 조직, 전략적 수준에서의 적응능 력을 의미한다(Volberda, 1997). 유연성을 확보하는 것은 실행에 의한 학습을 향상시키고(활동 적인 유연성), 많은 비용과 몰입을 하지 않고 지식의 원천에 대한 전환(조직적인 유연성), 그 리고 이러한 학습원천을 전략적으로 이용하는데 있어서도 유연성(전략적 유연성)을 가지게 되어 기업의 지식역량의 확장을 가져 올 수 있다. 최근에는 사회적 네트워크가 유연한 학습 을 위한 새로운 조직 구조로 많이 제시되고 있다 ${ }^{9}$ (eg; Cohen \& Levinthal, 1990; Daft \& Lewin, 1993; Liebskind et al., 1996). 특히 환경이 격변하는 산업에서는 학습으로 인한 매몰비용이 높 기 때문에 전략적 유연성을 유지하는 것이 매우 중요하다(Camagni, 1989; Teece, 1989).

전략적인 측면에서 관리된 투명성(개방성)과 유연성을 확보하기 위한 구조적인 측면에 서 유기적인 구조가 중요하고 유기적인 조직은 신제품 개발 또는 혁신의 성공요인으로서 중 요한 요소이다. 신제품 성공 요인에 대한 기존의 연구들은 외부환경에 대한 기업의 적응력 에 있어 관료제적인 구조보다는 유기적인(organic)구조가 더 유용하다고 주장한다(eg; Burns \& Stalker, 1971, 1995; Capon et al., 1992). Miles \& Snow(1992)는 유기적인 조직의 구성원은 상호 의존성을 인식하고 협력하려는 의지를 갖고 조직의 효과성을 유지하기 위하여 정보를 공유 한다고 주장하고 있으며 학습 조직의 연구에서는(Mintzberg, 1987; Gupta \& Govindarajan, 1991; Hart, 1992; Woodman, Sawyer, \& Griffin, 1993) 효과적인 정보공유는 정보흐름에 대한 체계적이 고 구조적인 제한이 해체되는 것을 요구하며 환경 불확실성이 높은 상황하에서 지식의 효과 적인 확산을 위해서는 조직 단위간에 커뮤니케이션의 빈도를 높이고 과정에서의 공식성을 낮추는 것이 필요하다고 주장하였다. 효과적인 정보 공유에 의하여 증가된 학습능력이 조직 혁신에 영향을 주게 된다. 이러한 주장은 개념적인 연구에서(eg; Stata, 1989; Tushman \& Nadler, 1986)와 실증적인 연구(Cohen \& Levinthal, 1990; Henderson \& Clark, 1990) 그리고 시뮬레이션을 통한 연구(eg; Mezias \& Glynn, 1993)에서 입증되었으며 조직의 학습능력은 조직의 새로움과 변화의 능력에 영향을 미치게 되는 것이다.

\footnotetext{
9 모든 연구가 사회적 네트워크의 유용성을 지적하고 있는 것만은 아니다. Hagedoorn \& Schakenraad(1994)는 혁신적인 기업이 전략적인 파트너링에 많이 참여하고 있다는 결과는 있지만 전략적인 파트너링과 성과간의 명확한 관계는 없다고 주장하며 강력한 네트워크 관계가 복잡성을 증가시키고 자율성을 침해하고 정보의 불균형과 같은 단점과 해이(hazard)을 가져올 수 있다(Hagedoorn, 1995) 1999.9 
Proposition 2: 유기적인 신제품 개발 조직의 투명성은 학습의 범위를 확장하여 신제품 개발 조직의 지식 역량을 향상시킨다.

Proposition 3: 유기적인 신제품 개발조직은 구성원간의 커뮤니케이션의 품질을 높여 신 제품 개발 조직의 지식역량을 향상시킨다.

\section{3 신제품 개발 조직 구성원의 몰입과 자율성}

불확실성이 높은 상황인 신제품 개발 과정에서는 효과적인 정보 공유를 위한 상호 호혜 성과 신뢰 그리고 구성원들의 신제품 개발 프로젝트에 대한 몰입이 전제되어야 한다. 몰입 은 상호간의 협력의 가능성을 높이는 행동(Gulati et al., 1994)으로서 조직의 목적에 대한 구성 원의 몰입은 구성원간의 강력한 네트워크를 형성하며 구성원간 신뢰의 바탕이 되어 사회적 인 규범을 제공한다(Macneil 1980). 신제품 개발과정에 참여하고 있는 구성원들의 상호의존 성에 의한 갈등을 해결하는데 있어 몰입이 긍정적인 영향을 미친다. Nonaka(1994)의 경우 이 러한 개인들의 몰입을 증가시키는 요인의 하나로서 의도(intention) ${ }^{10}$ 를 제시하고 있는 데 Nonaka 가 제시하는 의도는 유기체로서의 인간이 환경에 대한 적응과 생존을 위한 활동지향 적인 의도로서 환경과 상황에 대하여 어떻게 의미를 형성하고 이해하는가와 연관되어 있는 목적지향적인 의식으로서의 의도를 말한다.

신제품 개발 과정에서 구성원의 몰입을 유도하기 위하여 구성원의 지식 창출 행동에 대 한 자율성의 요소가 중요시 된다. 자율성(autonomy)은 각자 다른 의도를 가지고 있는 조직 내의 개인들은 지식을 창출함에 있어 정보의 획득, 인과관계의 설정, 해석에 있어서 상당한 정도의 탄력성을 유지하려고 한다(Nonaka, 1994). 자율성의 원리는 개인, 집단, 조직의 수준 에서 분리되어나 통합되어 활용되어질 수 있다. 자율적으로 활동하게 하기 위해서는 예상하 지 못한 기회의 가능성을 증가시키는 것이 필요하다(Cohen et al., 1972). 중요한 것들만 최소 한으로 명시되어 자율성이 보장되는 시스템(Morgan, 1986)은 자기화 조직(self-organization)의 기초를 형성하게 되고 개인의 자율성은 지식의 창출에 동기를 부여할 가능성을 높인다. 목 적성과 자율성은 조직에서 중요한 요소이며 목적은 개념화의 기초로서 작용하며 자율성은

\footnotetext{
${ }^{10}$ Edmund \& Husserl(1968)은 그 자체로서의 의식(consciousness)을 부정하고 어떤 대상에 주의를 기울이는 경우 의식이 발생한다고 하였다. 의식은 어떤 대상에 대한 의식이며 이는 대상에 대한 주체의 몰입에 따라 발생하고 지속되고 사라진다고 하였다(Nonaka, 1994).

1999.9

신제품 개발조직의 지식역량 향상 66
} 
지식을 흡수하는 개인의 자유를 제공한다(Nonaka, 1994). $3 \mathrm{M}$ 조직에서의 개인연구활동의 자 율성은 신제품의 개발능력을 향상의 예로서 자주 제시되고 있다.

구성원의 몰입과 더불어 최고(상위)경영층의 몰입도 상당히 중요한데 이는 최고(상위)경 영층의 몰입은 신제품 개발조직의 구성원에게 매력적인 자원(재무적/정치적 자원)을 제공하 며 개발과정의 진행에 대한 인정(approval)과 신제품 개발을 자극하는 인센티브를 제공할 수 있다(Brown \& Eisenhardt, 1995). Imai et al.,(1985)이나 Tacheuchi \& Nonaka(1986)의 연구에서는 이러한 최고(상위)경영층의 몰입이 '미묘한 통제(subtle control)'를 제공함으로써 우수한 과정 적인 성과나 효과적인 제품을 산출할 수 있다고 주장하고 있다. '미묘한 통제'는 신제품 개발 조직에게 대표권(delegation)을 부여하여 창조성에 대한 자율성을 보장하며(Brown \& Eisenhardt, 1995) 동기 부여를 통한 효율적인 제품 개발과정을 유도할 수 있다는 것이다. 신제품 성과 의 영향 변수에 대한 실증적인 연구에서도 최고(상위)경영층의 신제품 개발과정에 대한 몰 입을 제시하고 있다(Zirger \& Maidique; 1990; Cooper \& Kleinschmidt, 1987; Souder \& Song, 1998).

Proposition 4: 신제품 개발조직 구성원의 몰입과 자율성은 상호 신뢰를 높여 신제품 개 발 조직의 지식역량을 향상시킨다.

\section{4 정보 기술 하부구조(inf rastructure)의 구축}

정보 기술(information technology)은 신제품 개발 조직의 지식 역량 향상에 매우 중요한 역할을 차지한다. 지식의 형상화 과정이 신제품 개발과정이므로 지식은 정보적 형태로 개인 간 혹은 조직간 이동되기 때문에 수단(enabler)으로서의 정보 기술의 활용은 지식의 통합에 중요한 역할을 수행하게 된다. 특히 오늘날의 경영현상이 유연생산과 유연 마케팅에 의한 고객화된 제품(customized product)의 중요성이 높아짐에 따라 고객, 경쟁, 기술 상황에 대한 정보의 획득과 기업 내 축적된 지식과의 결합 과정에서 정보기술은 기업의 활동을 효율화할 수 있는 하부구조(infrastructure)적인 성격을 가지고 있는 것이다.

조직간 시스템의 연결 수단으로서의 정보 기술의 활용은 조직간 협력(조정 능력)을 원 활하게 수행할 수 있도록 함으로써 조정에 대한 비용(내부 조정 비용, 외부조정 비용: 지식 획득 거래비용)을 감소시킬 수 있다. 정보 기술은 정보의 흐름을 원활하게 함으로써 혁신의 과정에서 발생하는 많은 갈등적인 요소를 조정하는 수단으로서 역할을 수행한다. 또한 정보 기술을 활용함으로써 물리적인 거리를 극복할 수 있다. 또한 지식을 유지 변환하는 과정에 
서의 데이터 베이스는 조직 기억화의 효율성과 효과성을 높인다.

신제품 개발과정에서 정보 기술의 활용과 관련하여 지식(정보)의 부호화와 부호화된 지 식의 전용성(appropriability) 유지의 문제를 고려한 정보 기술의 구성(architecture)이 중요하다. 또한 이러한 측면에서의 신제품 개발조직의 지식관리에는 지식의 개량화를 함께 고려하여야 한다.

Proposition 5: 정보 기술의 활용은 조직 기억, 신제품 개발조직의 내/외적 커뮤니케이션 의 효율성을 높여 신제품 개발 조직의 지식역량을 향상시킨다.

[표 6] 지식 역량 형성의 조건

\begin{tabular}{|c|c|}
\hline \multirow{2}{*}{ 문화 (분위기) } & 조건 \\
\cline { 2 - 3 } & 학습의도(Learning Intent); \\
\hline \multirow{2}{*}{ 구조 } & 창조된 불확실성, 파동(fluctuation) \\
\cline { 2 - 3 } & 투명성(개방성): 관리된 투명성 \\
\hline \multirow{2}{*}{ 구성원 } & 유연성: $\quad$ 활동유연성/조직 유연성/전략적 유연성 \\
\cline { 2 - 3 } & 자율성 \\
\hline \multirow{2}{*}{ 정보 기술 } & 몰입 \\
\cline { 2 - 3 } & 정보 기술을 이용한 조직 기억 \\
\hline
\end{tabular}

\section{6. 결론}

본 연구의 기본적인 전제는 경쟁우위 원천이 산업의 구조나 산업 내에서의 기업의 특권 화된 지위에서 발생한다는 경쟁구조(Competitive Force)이론이나 전략갈등(Strategic Conflict)이 론과는 달리 기업의 경쟁우위 원천은 기업 내부의 특유한 자원(firm specific resource)-특히 지 식-과 자원의 결합과정으로서의 역량(firm specific competence)-특히 지식 역량-이 경쟁우위를 창출한다는 관점을 지지한다. 이러한 관점 하에서 본 연구에서는 지식 결집체로서 신제품 개발조직(팀)이 보유하고 있는 지식과 신제품 개발과정에서 지식을 어떻게 활용하는가가 가 치의 창출은 물론 경쟁우위의 형성과 유지의 근거가 됨을 제시하고 있다. 
이러한 측면에서 본 연구에서는 지식역량의 구성요소와 지식역량 형성에 영향을 미치는 요인들에 대한 개념적인 연구를 수행하였다. 그리고 신제품 개발 과정은 팀(Team)에 의존하 여 이루어지는데 본 연구에서는 과거의 연구와는 달리 분산된 인지 개념을 활용하여 신제품 개발 팀에 대한 새로운 인식을 부가하였다. 즉, 신제품 개발 팀은 지식생산활동에 참여하고 있어 팀의 사회적인 과정에 대한 이해와 인지적인 관점에서의 이해가 상호 보완적으로 결합 되어져야 함을 제시하고 있다.

[그림 3] 신제품 개발조직의 지식역량 형성의 독자적 메커니즘

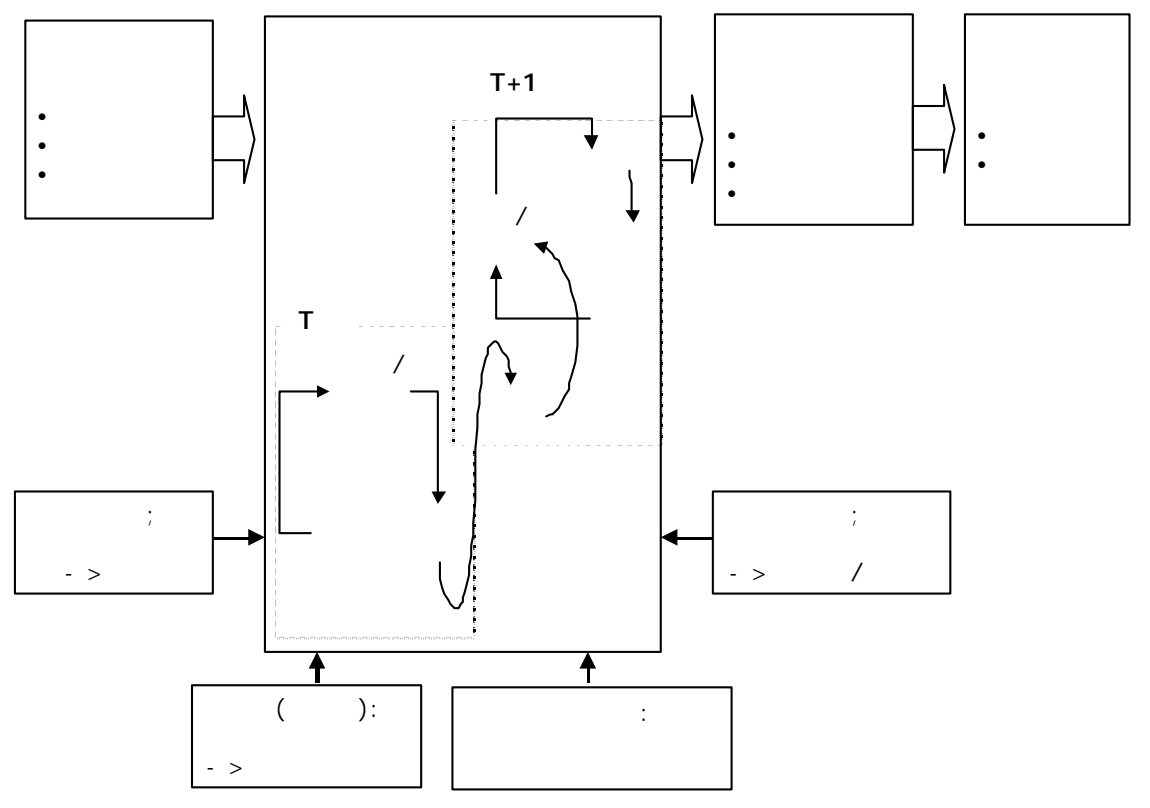




\section{참고문헌}

김 기찬(1992), "기업간 관계모형의 개발에 관한 연구", 서울대학교 박사학위 논문.

김 원수(1992), 「신제품 개발론」, 서울: 경문사.

이 유재· 박 찬수 편역(1995), 「신상품 마케팅」, 서울: 시그마프레스.

임 종원, 김 기찬(1989), "신제품개발의 성공요인 분석," 중소기업 연구, 제 11 권, 제 1 호, pp.133-162.

오 창호(1994), "경로 시스템의 설계 및 평가를 위한 구성원리의 모색과 그 유효성에 관한 연구-정보처리와 커뮤니케이션 과정을 중심으로-", 서울대학교 대학원 박사학위 논문.

오 태현(1995), "마케팅 부서와 타부서의 협력에 관한 연구-협력조성방식을 중심으로-", 서울 대학교 대학원 박사학위 논문.

윤 태석(1992), "신제품 성공의 요인간 관계에 관한 연구-소비재를 중심으로-" , 서울대학교 대학원 박사학위 논문

조 호현(1995), "마케팅 관계화의 시스템에 관한 연구- 정보 기술을 중심으로", 서울대학교 대학원 박사학위 논문.

Abernathy, W. J. \& J. M Utterback(1978), "Patterns of Industrial Innovation," Technology Review, June/July.

Adams, M. E., G. S. Day, \& Deborah Dougherty(1998), "Enhancing new product development performance: an organizational learning perspective," Journal of Product Innovation Management, Sept, v15, n5, p403(20).

Allee Verna(1997), The Knowledge Evolution: Expanding Organitional Intelligence, ButterworthHeinenmann.

Allen M. Weiss \& Jan B. Heide.(1993), "The nature of organizational search in high technology markets," Journal of Marketing Research, May, v30, n2, p220(14).

Ali, A., R. Krapfel, \& D. Labahn (1995) "Product in innovativeness and entry strategy: Impact on cycle time and break even time, Journal of Product Innovation Management, 12, pp.54-69.

Amidon, Debra, M.(1997), Innovation Strategy for The Knowledge Economy: The ken Awakening, Butterworth-Heinemann.

Amit, R. \& P. J. H. Shoemaker(1993), "Strategic Asset and Organization Rent," Strategic Management 1999. 9 
Journal, v14, p.38.

Barney, Jay(1991), "Firm resources and sustained competitive advantage," Journal of Management, March, v17, n1, p99(22).

Bergen, M., S. Dutta \& O. C. Walker Jr.(1992), "Agency relationships in marketing: a review of the implications and applications of agency and related theories," Journal of Marketing, July, v56, n3, $\mathrm{p} 1(24)$.

Bharadwaj, S. G. \& P. R. Varadarajan \& J. Fahy(1993), "Sustainable Competitive Advantage in Survice Industries: A Conceptual Model and Research Propositions", Journal of Marketing, v 57, Oct, pp. 8396.

Brown S. L. \& K. M. Eisenhardt(1995), "Product Development: Past Research, Present findings, and Future Direction, Academy of Management Review, v 20(2).

Brynjolfsson, E., A. A. Renshaw \& M. Van Alstyne(1997), "The matrix of change," Sloan Management Review, Winter, v38, n2, p37(18).

Capon, N. \& R. Glazer(1987), "Marketing and Technology: A Strategic Coalignment," Journal of Marketing, v 51(3).

Cohen, W. M. \& D. A. Levinthal(1990), "Absorptive Capacity: A new Perspective on Learning and Innovation", Administrative Science Quarterly, 35(1), pp.128-152.

Conner K.R. \& C.K. Prahalad(1996), "A Resource - Based Theory of the Firm: Knowledge Versus Opportunism", Organization Sciences, v 7, 5, Sep-Oct, pp.477-501.

Cooper, R. G., \& E. J. Kleinschmidt(1994), "Determinants of timeliness in product development, Journal of Product Innovation Management, 11, pp.381-396.

Daft, R. L. \& R. H. Lengel(1986), "Organizational information requirements, media richness and structural design," Management Science, May, v32, n5, p554(18).

Demarest, M.(1997), "Understanding Knowledge Management", Long Range Planning, v 30, 3, pp.374384.

Dierickx, I. \& K. Cool(1989), "Asset stock accumulation and sustainability of competitive advantage," Management Science, Dec, v35, n12, p1504(8).

Dougherty, Deborah(1992), "A Practice-Centered Model of Organizational Renewal Through Product Innovation", Strategic Management Journal, Summer. 
Duncan, Tom \& Sandra E. Moriaty(1998), "A Communication-Based Marketing Model for managing Relationships," Journal of Marketing, v 62, Apr., pp. 1-13

Eisenhardt, K. \& B. N. Tabrizi(1995), "Accelerating adaptive processes: product innovation in the global computer industry," Administrative Science Quarterly, March, v40, n1, p84(27).

Garud, R. \& P. R. Nayyar(1994), "Transformative capacity: continual structuring by intertemporal technology transfer," Strategic Management Journal, June, v15, n5, p365(21).

Ghingold, M. \& J. Bruce(1997), "Technical knowledge as value added in business markets," Industrial Marketing Management, May.

Glazer, Rashi(1991), "Marketing in an information-intensive environment: strategic implications of knowledge as an asset," Journal of Marketing, Oct, v55, n4, p1(19).

Granovetter, M.(1985), "Economic action and social structure: A theory of embeddedness," American Journal of Sociology, v 91, 481-510.

Grant R.M.(1996), "Toward a Knowledge-Based Theory of the Firm." Strategic Management Journal, v 17(Winter Special Issue), pp.109-122.

Guy, K. \& Georghiou, L.(1991), The Alvey Programme on Advanced Information Technology, HMSO, London.

Hagedoorn, J. \& J. Schakenraad,(1994), "The effect of strategic technology alliance on company performance," Strategic Management Journal, v 15, pp.291-309.

Hamel. Gary(1991), "Competition for competence and inter-partner learning within international strategic alliances," Strategic Management Journal, Summer, v12, nSPEISS, p83(21).

Hayes, R. H. \& R. Jaikumar(1988), "Manufacturing's Crisis: New Technologies, Obsolete Organizations," Harvard Business Review, Sep/Oct.

Hedlund, G.(1994), "A model of knowledge management and the N-form corporation," Strategic Management Journal, Summer, v15, nSPEISS, p73(18).

Heide, J. B. \& Allen M. Weiss.(1995), "Vendor consideration and switching behavior for buyers in hightechnology markets," Journal of Marketing, July, v59 n3 p30(14)

Hunt, S. D. \& R. M. Morgan(1995), "The comparative advantage theory of competition," Journal of Marketing, April, v59, n2, p1(15).

Hunt, Shelby(1997), "Resource-Advantage Theory: An Evolutionary Theory of Competitive Firm 1999. 9 
Behavior?, " Journal of Economic Issues, v 31(1), Mar.

Hurley R.F. \& G. T. Hult(1998), "Innovation, Market Orientation, and Organization Learning: An Integration and Empirical Examination," Journal of Marketing, v 62, July, pp.42-54.

Iansiti, M.(1993), "Real-world R\&D: jumping the product generation gap," Harvard Business Review, May-June, v71, n3, p138(10).

Itami, H \& T. Numagami(1992), "Dynamic interaction between strategy and technology," Strategic Management Journal, Winter, v13, nSPEISS, p119(17).

Jassawalla, A. R. \& H. C. Sashittal(1998), "An examination of collaboration in high-technology new product development processes," Journal of Product Innovation Management, May, v15, n3, p237(18).

Jaworski, B. J \& Kohli, A. K.(1993), "Market orientation: Antecedents and consequences," Journal of Marketing, Jul.

Kahn. Kenneth B.(1996), "Interdepartmental integration: a definition with implications for product development performance," Journal of Product Innovation Management, March, v13 n2 p137(15)

Kleinschmidt, Elko J. \& Robert G. Cooper(1995), "The relative importance of new product success determinants- perception versus reality," $R \&$ D Management, v25, n3, July, p.281(18).

Kohli, A. K. \& B. J. Jaworksi(1990), "Market orientation: the construct, research propositions, and managerial implications," Journal of Marketing, April, v54, n2, p1(18).

Kogut B. \& Udo Zander(1993), "Knowledge of the Firm and the Evolutionary Theory of the Multinational Corporation" Journal of International Business Studies, 4th Quarter, pp.625-645.

Lilien, G. L. \& Eunsang Yoon(1990), "The timing of competitive market entry: an exploratory study of new industrial products?" Management Science, May, v36, n5, p568(18).

Li Tiger \& Roger J. Calantone(1998), The Impact of market Knowledge Competence on New Product Advantage: Conceptualization and Empirical Examination, Journal of Marketing, v 62, Oct., pp.1329.

Madhavan Ravindranath \& Rajiv Grover(1998), From Embedded Knowledge: New Product Development as Knowledge Management, Journal of Marketing, v 62, Oct., pp.1-12.

Maidique, Modesto A. \& Zirger, Billie Jo(1984), "A Study of Success and Failure in Product Innovation: The Case of the U.S. Electronics Industry", IEEE Transactions on Engineering Management, Nov 1999. 9 
Maidique, Modesto A. \& B. J. Zirger(1985), "The New Product Learning Cycle," Research Policy, Dec.

Miles, R. E. \& Snow, C.(1978), Organizational strategy, structure and process. New York: McGraw-Hill.

Nelson, R., \& S. Winter(1977), "In Search of Useful Theory of Innovation", Research Policy, v 6, pp.3676.

Nonaka(1994), "Dynamic Theory of Organizational Knowledge Creation," Organization Science, v, 5, No 1, Feb..

Nonaka, I. \& H. Takeuchi(1995), The Knowledge Creating Company, Oxford University Press, N.Y..

Ottum, B. D. \& W. L. Moore(1997), "The role of market information in new product success/failure," Journal of Product Innovation Management, July, v14, n4 p258(16).

Parry, Mark E. X. Michael Song(1994), "Identifying new product successes in China," Journal of Product Innovation Management, Jan, v11, n1, p15(16).

Prahalad, C. K. \& G. Hamel(1990), "The Core Competence of the Corporation", Harvard Business Review, 68(3), pp.79-81

Price, R.M.(1996), "Technology and Strategic Advantage," California Management Review, v 38, No. 3 , p. 43

Reed, R. \& R. J. DeFillipi(1990), " The Causal Ambiguity Barriers to Imitation, and Sustainable Competitive Advantage," Academy of management Review, v 15, Jan, pp/88-117.

Schilling, M. A .\& Charles W.L. Hill(1998), "Managing the new product development process: strategic imperatives", The Academy of Management Executive, August, v12, n3, p67(15)

Sinkula J.M.(1994), "Market Information Processing and Organizational Learning," Journal of Marketing, v 58, Jan..

Slater S. F. \& J.C. Narver(1995), "Market Orientation and the Learning Organization, Journal of Marketing, v 59, July., pp.63-74.

Song, X. Michael \& Mark E. Parry(1997), "Teamwork barriers in Japanese high-technology firms: the sociocultural differences between R\&D and marketing managers," Journal of Product Innovation Management, Sep, v14, n5, p356(12).

Song, X. M. \& Mitzi M. Montoya-Weiss(1998), "Critical development activities for really new versus incremental products," Journal of Product Innovation Management, March, v15, n2, p124(12).

Song X. Michael, Wm. E. Souder, \& Barbara Dyer(1997), "A Causal Model of the Impact of Skills, 1999. 9 
Synergy, and Design Sensitivity on New Product Performance," Journal of Product Innovation Management, 14 p.88-101.

Souder, W. E. \& X. Michael Song(1997), "Contingent product design and marketing strategies influencing new product success and failure in US and Japanese electronics firms," Journal of Product Innovation Management, Jan, v14, n1, p21(14).

Spender J.C.(1996), "Making Knowledge the Basis of Dynamic Theory of the Firm." Strategic Management Journal, v 17(Winter Special Issue), pp.45-62.

Stalk, G., P. Evans \& L.E. Shalman, (1992), "Competing on Capabilities: The New rules of Corporate Strategy," Harvard Business Review, March-April, pp.57-69.

Teece, David J., Gary Pisano \& Amy Shuen(1997), "Dynamic capabilities and strategic management," Strategic Management Journal, August, v18, n7, p509(25)

Teece David J.(1998), "Capturing value from knowledge assets: the new economy, markets for know-how, and intangible assets," California Management Review, Spring, v40, n3, p55(25).

Volberda, H. W.(1997), "Building flexible organizations for fast-moving markets," Long Range Planning, April, v30, n2, p169(15).

von Hippel, E., 'Appropriability of innovation benefit as a predictor of the source of innovation.' In The Economics of Innovation (ed. C. Freeman; 1982).

Walsh, J. P. \& G. R. Ungson(1991). "Organizational memory", Academy of Management Review, Jan, v16, $\mathrm{n} 1, \mathrm{p} 57(35)$.

Wernerfelt B.(1995), "The Resource-Based View of The Frm: Ten Years After, Strategic Management Journal, v 16, pp171-174.

Zirger, B. J. \& M. A. Maidique(1990), "A model of new product development: an empirical test." Management Science, July, v36, n7, p867(17). 